\title{
Teaching quality improvement in Tanzania: a model of inter- professional partnership for global health development
}

\author{
John Kvasnicka ${ }^{a}$, Ken Olson ${ }^{b}$, Mufwimi Saga ${ }^{c}$, Ignas Danda ${ }^{d}$, Randy Hurley ${ }^{e}$, Gary \\ Moody ${ }^{\dagger}$, Cindy Wilke ${ }^{g}$ \\ ${ }^{a} \mathrm{MD}, \mathrm{MBA}$, Shoulder to Shoulder, USA \\ ${ }^{\mathrm{b}} \mathrm{MD}$, Shoulder to Shoulder, USA \\ ${ }^{\mathrm{c}}$ AMO, Christian Social Services Commission of Tanzania \\ ${ }^{d}$ AMO, Christian Social Services Commission of Tanzania \\ e MD, Shoulder to Shoulder, USA \\ ${ }^{f} \mathrm{MD}$, Shoulder to Shoulder, USA \\ ${ }^{\mathrm{g}} \mathrm{MHA}$, Global Health Administration Partners, USA
}

\section{Abstract}

Background: Education is a universal need in health care and a tool for quality improvement. We developed a two-day medical education conference in Iringa, Tanzania, that has now evolved to teach the basics of quality improvement to an inter-professional audience from the 28 hospitals in the southern zone of the Tanzania Christian Social Services Commission (CSSC).

Methods: We describe the planning, budget, implementation, evolution and evaluation of this on-going medical education conference. Representatives from medicine, nursing, pharmacy and administration from all 28 hospitals were invited to attend. Attendees evaluated the conference and individual lectures on a 5 point scale. In addition, attendees were asked to rate the most important learning aspect of the conference.

Results: Over 100 Tanzanian health professionals and administrators from the 28 hospitals in the southern zone of the CSSC attended. Evaluation forms were completed by 82 attendees. The 2016 conference received an overall rating of 4.0 on a 5 point scale. The individual lectures received an overall rating of 4.2 on a 5 point scale. Quality improvement techniques and co-leadership topics were rated as most useful by attendees.

Conclusion: We provide a framework for developing a medical education conference that can be replicated in other settings. Teaching the basics of quality improvement by having hospital leadership teams develop individual quality improvement projects is a highly useful method of instruction.

Mar 2017. Christian Journal for Global Health, 4(1): 34-45. 


\section{Introduction}

Education is a universal need in healthcare. One of the most effective ways to scale up human resources for healthcare to reduce the global burden of disease is through education and training programs. ${ }^{1} \quad$ Developing effective global health education requires partners from developed and developing countries to work together to meet local educational needs. The supply of health workers in Africa is inadequate and expected to worsen. The ultimate goal of education, of course, is to strengthen health systems. ${ }^{2}$ This requires a global outlook, a multi-professional perspective, and a systems approach. $^{3}$ In this report, we describe the development and delivery of an ongoing healthcare education series through a partnership between faith-based organizations in the United States and Tanzania. The conference is designed to emphasize principles of quality improvement and the application to quality improvement plans by attendees following the conference. The principles and organization of this conference can be replicated in other settings to promote healthcare education and Christian service.

\section{Background}

Shoulder to Shoulder is a Christian nonprofit organization based in Minnesota that has partnered with Ilula Lutheran Hospital (ILH) in Ilula, Tanzania for the past 15 years to develop and improve the services provided to the local area by ILH. ILH is a 100-bed hospital in southern Tanzania which serves as a district hospital. Shoulder to Shoulder has partnered with ILH over these years on multiple programs, including development of hospital expansion, laboratory, operating rooms, better access to water and electricity, and advanced training programs for staff. Most recently, this partnership has supported the opening of a nursing school at the hospital.

Since 2014, Shoulder to Shoulder has presented the annual Ilula-Minnesota International Healthcare Conference. Our first course was presented in January 2014 with 30 attendees representing referral hospitals in the Southern Zone of the Christian Social Services Commission (CSSC), an ecumenical body formed to facilitate social services with the main focus on education and health services (http://www.cssc.or.tz/). Based on the high degree of positive feedback from the initial conference, our partners in Tanzania encouraged us to significantly expand the conference to offer this educational experience to a much larger audience of caregivers. As a result, we expanded the 2015 conference to include all 28 Southern Zone Hospitals of the CSSC with a total attendance of approximately 80 professionals. For the 2016 conference, we added an administrative track to our conference and invited over 100 attendees. This report describes the planning of the conference, outcomes, and feedback from participants. This description can serve as a starting point for organizations planning global health education programs.

The reasons for developing this conference have been supported by several observations. Table 1 lists the background observations and issues leading to the development of the conference.

Table 1. Background

- $\quad$ There is a great need for improved health care in developing countries.

- Education is a common and fundamental aspect of health development.

- Modeling education can help health care institutions develop an education culture and infrastructure.

- $\quad$ Effective programs should be able to scale and spread, and be sustainable. ${ }^{4}$

- Effective programs build on long-term partnerships.

- There is great interest among US health care workers in serving overseas, especially short term assignments.

- Actual service promotes greater engagement, lifelong commitment, and interest in global health service. ${ }^{5}$

- Health care workers have limited ability to volunteer based on constraints in time, expense, and professional and family commitments.

- $\quad$ Building relationships and providing moral support are important components of many programs. 


\section{Planning}

During the initial development of the program, the first priorities were to identify the purpose of the program and guiding principles. The purposes of the program were identified through the experiences of presenting educational opportunities at ILH over a number of years. In developing and presenting these programs, we iteratively defined a number of issues and opportunities that defined the purpose statements of our program. The purpose statements are listed in Table 2.

Table 2. Purpose Statements

- $\quad$ Provide learning opportunities for physicians, nurses, pharmacists, and administrators who staff CSSC Hospitals in Southern Tanzania.

- Promote a culture of lifelong learning and education.

- Foster inter-professional teamwork between nursing, pharmacy, medicine, and administration.

- Foster relationships with international development partners.

- Develop actionable quality improvement plans.

- Foster sustainable improvement in medical care and the health of communities in Southern Tanzania.

- Engage interest among U.S. health care professionals and students in contributing to global health development.

- Foster education of U.S. students (medical, pharmacy, nursing, and healthcare administration students and resident doctors-in-training).

- $\quad$ Provide U.S. volunteers with opportunity to learn about medicine in the developing world.

The next step in planning for the conference was the identification of guiding principles. Through dialogue with our Tanzanian partners, we identified five guiding principles for the conference, which would help in decision making as we develop and refine the conference (Table 3 ).

\section{Table 3. Guiding Principles}

1. Lifelong Learning: We believe all professionals should contribute to a culture of learning and continuously learn to improve their practice. We include students and residents in preparation for and presentation of the conference.

2. Inter-professional Teamwork: We include nurses, pharmacists, administrators, and physicians in both the attendance and presentations. ${ }^{6}$ We emphasize teamwork throughout the conference. We each bring unique knowledge and skills to share; specifically, Tanzanian presenters emphasize tropical medicine and HIV, and American presenters emphasize the growing global problem of chronic and non-communicable diseases.

3. Mutual Respect: We emphasize the ability of all our participants to teach and learn from each other regardless of differences in practice setting, culture, and socio-economic situation. We include local leaders in planning the conference and select topics based on feedback from participants. ${ }^{7}$ Presentations are delivered by both U.S. and Tanzanian professionals. We adhere to the highest international standards in the preparation of the educational content and accreditation of the program. ${ }^{8}$ The program is based on the foundation of a longstanding and ongoing relationship.

4. Continuous Improvement: Learning should drive improvement in practice. ${ }^{10} \mathrm{We}$ include education on principles and tools for developing quality improvement plans. Each team prepares a specific quality improvement plan to implement upon returning to home hospitals. ${ }^{11}$

5. Sustainable Impact: We believe that education and improvement are some of the most valuable ways to promote a lasting and sustainable positive impact on the health of our partner's communities. ${ }^{12}$

The content of the initial course was based on discussions with our Tanzanian colleagues. The content for subsequent courses has been based on learning needs identified by participants from the previous conference. General learning objectives are listed in Table 4. 
Table 4. Learning Objectives

- Participants will learn current concepts and techniques in medical care in the acute hospital setting.

- Participants will be able to compare and contrast current practices in U.S. hospitals and Tanzania hospitals. Reasons for differences will be highlighted.

- Participants will develop quality improvement action plans for their own hospitals based on learning from the presentations and skills lab.

Learning formats included didactic lectures, question and answer sessions, skills labs, and group sessions to develop quality improvement plans. A total of 12.5 hours of instruction was provided.

In planning the conference, we adhered as closely as possible to the highest international educational standards. ${ }^{13}$ As such, the conference received approval from the Education Department at the HealthEast Care System to provide participants with continuing medical education (CME) credits for participation in this program.

A planning committee is responsible for planning the conference and fundraising. This committee includes physicians, pharmacists, administrators, and nurses. We include healthcare professionals from both the U.S. and Tanzania, and communicate via in-person meetings as well as email.

A key element of the conference is including planning for quality improvement throughout the conference. Principles of effective quality improvement in health care are covered early in the conference. Throughout the conference, we emphasize utilizing the material to develop quality improvement plans. The conference concludes with teams selecting a quality improvement project based on material covered in the conference, and planning to implement the quality improvement plan upon returning to their home institutions.

\section{Conference implementation}

The initial conference was presented at ILH in a conference room. Subsequent conferences have required a larger space and have been presented at an educational facility in Iringa, Tanzania. Facilities are available for classroom presentations, and separate areas are available for skills labs and presenter preparation.

The conference occurs over two days in January each year. Attendance is by invitation. We have invited the following from each of the 28 CSSC Southern Region Hospitals: 1 practicing physician, 1 pharmacist, 1 practicing nurse, 1 administrator. In addition to the above, we invite 6 staff from ILH, 10 staff from Iringa Government Hospital, and 4 invited guests.

Due to limitations in resources in Tanzanian hospitals, presentations focus on topics that are appropriate to the environment. Presentations are designed to focus on pathophysiology, pharmacology, history and physical, diagnostics, and treatments appropriate to the local environment.

In order to accommodate a variety of learning styles, the presentations feature didactic and skills instruction supported by peer-reviewed data, utilizing lecture and small-group discussion formats.

Learning topics are identified in partnership with our Tanzanian colleagues and expertise of our volunteer faculty. We attempt to include Tanzanian presenters. Our ideal goal would be 50\% U.S. and $50 \%$ Tanzanian presenters, but we have not achieved this ratio yet. To date we have only had $10-20 \%$ of presentations by Tanzanian health professionals.

CME credit has been approved by an organization in the United States that is accredited by the ACGME to provide level $1 \mathrm{CME}$ credit. Although this may not specifically be required, or even valued by participants, we feel it is important to adhere to the highest international educational standards in whatever environment the education is 
delivered. This is the same standard we would require for $\mathrm{CME}$ in the United States.

Funding for the conference is provided from fundraising conducted throughout the year. We have attempted to maintain a diversified group of donors in order to sustain stable funding that is not dependent on a single donor. Funding has been provided by foundations, nonprofit organizations devoted to global health, and generous individuals. Most participants and faculty involved in the program have provided all services on a volunteer basis without any compensation, and have been fully responsible for all costs of their own transportation, travel expenses, and living expenses while volunteering to serve in this program. Some faculty and students have conducted independent fundraising to support their travel expenses.

Ilula International Conference provides support for attendees including bus fare based on their receipts and lodging. Refreshments and lunches are provided at the conference. Incidental expenses and additional meals, e.g., dinner, are the responsibility of the attendees or their home institutions. There is no per diem paid to attendees for attendance. Total cost of the 2016 conference was $\$ 15,546$. (This does not include cost of travel for expatriate volunteers who cover their own travel costs.) An example of our budget spreadsheet is shown in Table 5.

Table 5. Budget Spreadsheet

\begin{tabular}{|c|c|c|c|c|c|}
\hline Item & Number & Days & Cost/person & Total & US\$ \\
\hline Travel costs reimbursed for attendees & 118 & & TZS 60,000 & TZS 7,080,000 & $\$ 3,218$ \\
\hline Lodging costs reimbursed for attendees & 118 & 3 & TZS 150,000 & TZS $17,700,000$ & $\$ 8,045$ \\
\hline Meals & 153 & 2 & TZS 31,000 & TZS $4,743,000$ & $\$ 2,156$ \\
\hline Lecture Hall Rental & & & & TZS 200,000 & $\$ 91$ \\
\hline Local Course Directors honorarium & & & & TZS 960,000 & $\$ 436$ \\
\hline Honorarium for invited TZ faculty & 6 & & TZS 100,000 & TZS 600,000 & $\$ 273$ \\
\hline Local Secretary & & & & TZS 40,000 & $\$ 18$ \\
\hline Local car and fuel costs & & & & TZS 200,000 & $\$ 91$ \\
\hline Copying Costs & 725 & & TZS 150 & TZS 108,750 & $\$ 49$ \\
\hline Folders & 145 & & TZS 500 & TZS 72,500 & $\$ 33$ \\
\hline Writing Books & 118 & & TZS 1,500 & TZS 177,000 & $\$ 80$ \\
\hline USB Drives & & & & & $\$ 500$ \\
\hline Pens & & & & & $\$ 250$ \\
\hline Conference Costs Subtotal & & & & & $\$ 15,241$ \\
\hline Wire Transfer Surcharge Add 2\% & & & & & $\$ 305$ \\
\hline Total & & & & & $\$ 15,546$ \\
\hline
\end{tabular}

\section{Results}

Assessment of the value of the course is determined from attendee evaluations. Attendees rated the value of the conference on evaluation forms at the end of the conference in January 2016. Of 87 local attendees, 82 completed the evaluation forms at a $94 \%$ completion rate. The evaluation form is available in the appendix. All results presented here are evaluations from local Tanzanian attendees, not from U.S. volunteers.

Overall evaluation results from our 2016 conference are as follows: When asked to rate the overall value of the conference on a scale of 1-5, responses averaged 4.0. Individual lectures were evaluated on a 5 item Likert scale (rating of 5 most valuable). The average lecture score was 4.2. All respondents felt that their competence had increased as a result of attending the conference.

Attendees were asked to answer comments, including the most important things they learned. The categories of the most important things learned from our 2016 conference in order of importance were: 1. Quality Improvement; 2. Co-leadership; 3. 
Hand hygiene; 4. Diabetes; 5. Wound care and cancer (tie).

Attendees were also given the opportunity to provide open-ended comments. Representative verbatim positive comments are shown in Table 6. Representative verbatim opportunities for improvement are shown in Table 7.

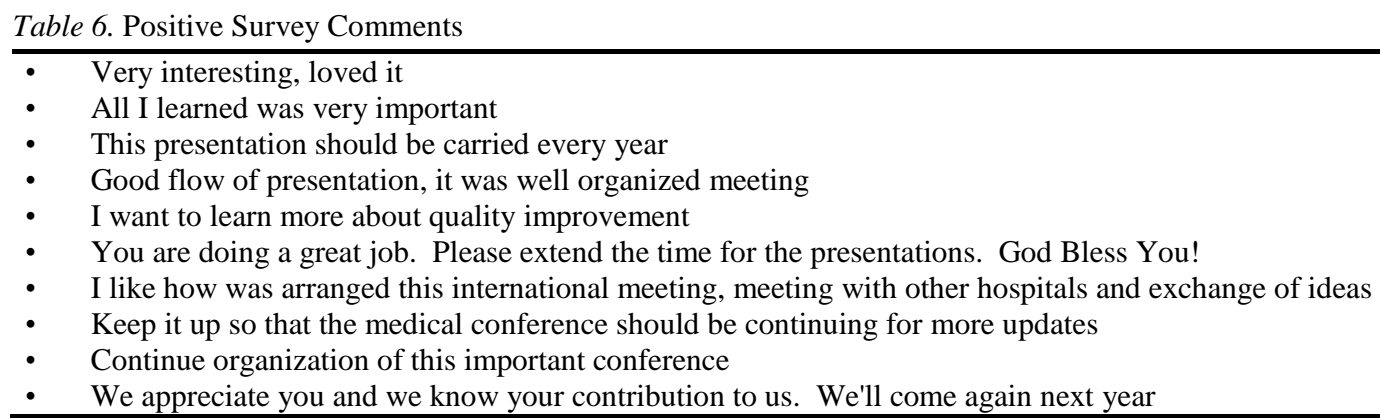

Table 7. Opportunities for Improvement

- More learning on leadership, management in hospital

- Topics on quality improvement should have more time

- Reduce speed of teaching

- Per Diem to be paid early to meet all expenses

- Please extend the time for presentations, 2 days are not enough

- Management of diabetes mellitus and cardiovascular diseases should be taught in detail

- American English difficult

- After each session, especially for disease, you have to elaborate more on drug of choice.

- Time for conference is too short (days)

\section{Discussion}

We describe the principles and practical aspects of an international educational series based on Christian principles to promote health in Tanzania. This series is embedded within a longstanding relationship between a U.S. nonprofit organization and a health system in Tanzania. ${ }^{14}$ The partnership represents a longstanding mutual commitment based on common Christian faith. Historically, missionary medicine was focused on spreading religion as well as healthcare. Today, many global health mission efforts are more secular. ${ }^{15}$ This conference series is part of a core value of the partnership described as creating, "A culture of education."

One of the key elements of our program is a focus on inter-professional team work. The importance of collaborative team work has increasingly been recognized, and elements of interprofessional education and collaborative practice have been shown to be beneficial. ${ }^{16} \mathrm{We}$ intentionally utilize professionals from multiple disciplines within our teaching faculty, and invite teams with multiple professionals from each hospital to participate in the conference. Throughout the conference, we emphasize the importance of teamwork, communication, collaboration, and mutual support. We have received anecdotal feedback that this emphasis has improved the functioning of teams when they return to their local hospitals.

An important principle in the planning and execution of our conference is the focus on partnership and mutual respect. ${ }^{17}$ Studies have demonstrated a low-level alignment between curriculum in global health programs and local community health needs. ${ }^{18}$ We recognize that the local health professionals are the experts, both in the local disease patterns, health issues, and availability of resources. We focus on shared 
learning with each group bringing unique expertise to share. It has been recognized that the implementation and ethics of sending healthcare professionals from high income countries is often not in concert with the skills required upon arrival in the destination country. ${ }^{19}$ Assuring alignment with the needs of the local community requires partnership throughout the planning and implementation process. ${ }^{20}$

Continuous quality improvement is a major focus that has increased over the years during our conference. Throughout the conference we emphasize utilizing the lessons from each of the lectures to develop specific quality improvement plans at the local level. One of the first lectures is on quality improvement utilizing the Institute for Healthcare Improvement model for improvement focusing on plan-do-check-act cycles (PDCA). ${ }^{21}$ The final day of the conference devotes time for each team to develop a specific quality improvement plan to implement upon return to their local hospital. Teams present these plans for shared learning purposes. ${ }^{22}$

Evaluation of global health education and training programs should include leadership development, effects on health care systems, and health outcomes. ${ }^{1}$ So far our evaluation has been limited to surveying results from attendees. We have been working to expand the evaluation process through development of quality improvement plans as an integral part of the course which will ultimately include measurement of impact. ${ }^{23}$

Core competencies for engaging in effective health promotion have been identified. These include catalyzing change, leadership, assessment, planning, implementation, evaluation, ${ }^{24}$ advocacy, and partnership. ${ }^{25}$ Other authors have identified required competencies and understanding the burden of global diseases, traveler's medicine, and immigrant health. ${ }^{26}$ We utilize extensive input from our Tanzanian partners and feedback from attendees to identify learning objectives and course content to assure appropriate content. We intentionally adhere to rigorous U.S. standards for certification of our educational content to assure quality of education, and respect the importance of common standards. ${ }^{9}$

A major part of our team represents students in various disciplines in healthcare from the United States who travel with our team and participate in the conference. ${ }^{27}$ There has been a surge of interest in global health learning opportunities among the next generation of medical professionals. ${ }^{16}$ This involvement of health professionals early in their career promotes an ongoing lifetime interest in global health. ${ }^{28,29}$ We also believe this model demonstrates the importance of teaching and learning as part of professional obligation to our partners in Tanzania. However, it should be recognized that including students and residents in presenting at the conference presents limitations and challenges in maintaining acceptable quality standards for educational content. All presentations by U.S. students and residents are approved by our CME sponsor and supervised by faculty to assure that the presentations meet educational standards.

In addition to the benefits to patients and staff in Tanzania, participation in this program provides a unique opportunity for volunteer U.S. physicians, nurses, pharmacists, administrators, and students by promoting engagement in the profession, providing an opportunity to serve and learn about medicine in the developing world, engaging interest in contributing to global health development, and fostering a culture of education. ${ }^{30,31}$ The short duration of this program allows health care professionals to contribute to medical mission work with limited time commitment while avoiding the well-described potential unintended consequences of short term medical mission work. ${ }^{32,33}$ By focusing on capacity building and education, rather than providing actual medical care, we have attempted to avoid the well-described risks of mission work which may actually degrade health system development.

The financial aspects of the conference are important to note. We provide reimbursement for travel, lodging, and food expenses for local participants. The costs of this are funded by 
generous donations from a variety of organizations and individuals in the United States. Fundraising has been one of the ongoing challenges in creating a sustainable model. Local custom in Tanzania includes paying participants in the educational conferences a per diem fee, or "sitting fee." This is not a common practice in the United States, and this issue has represented a cultural conflict in expectations. In particular, some of our funding organizations have policies against paying a per diem for educational conferences. As such, we have eliminated payment of the per diem. We are transparent about this issue with organizers and attendees; however, it has been an ongoing source of negative feedback from some of the attendees. In addition to development of the healthcare workforce, motivation of health workers to continue lifelong learning is a critical factor. Financial incentives for participation are undoubtedly important. However, studies have demonstrated that financial incentives alone are not sufficient to motivate health workers. Recognition is highly influential in health worker motivation. ${ }^{34}$ We provide CME certificates to all attendees to recognize their participation.

Recognizing and understanding cultural differences have both been some of the challenges in organizing this effort, and some of the greatest rewards as we expand our horizons and overcome challenges. ${ }^{15}$ Our common faith tradition represents one of the deepest connections between cultures and has been an enduring source of strength in this effort.

We are fortunate in that the language barrier has not been a significant issue since medicine is practiced in English in Tanzania in spite of the national language being Swahili. We do not need to use translators or interpreters in our conference.
However, English skills are somewhat variable in our attendees, and we have received some feedback regarding difficulty in understanding some of the presentations. Speaking slowly and clearly are ongoing challenges for our presenters.

We intend this report to serve as a potential resource for global health workers serving in Christian mission. The description of our principles and the program that has evolved can provide a starting point for individuals and organizations developing similar programs.

Ultimately, medical education should result in improved health. We hope to develop mechanisms to measure the impact this program has on multiple dimensions including health care system effectiveness, inter-professional teamwork, continuous quality improvement, and ultimately health benefits in southern Tanzania. Given resource limitations, we were unable to include such measurements. Our assessment is limited to immediate feedback from attendees and anecdotal reports. In the future, we intend to ask participants to return with reports of the results of implementing the quality improvement plans developed at the conference. This will serve multiple purposes: measurement of outcomes, shared learning regarding implementation challenges, accountability, and encouragement in the difficult work of quality improvement.

Our efforts have been focused on aligning the curriculum with local health needs, focusing learning in community clinical settings, creating actionable plans based on lessons learned, and focusing on the needs of basic healthcare workers. ${ }^{19}$ We believe that creating a culture of improvement and lifelong learning is one of the most sustainable ways to create ongoing improvements in health care throughout the world. ${ }^{35}$ 
Course Participants

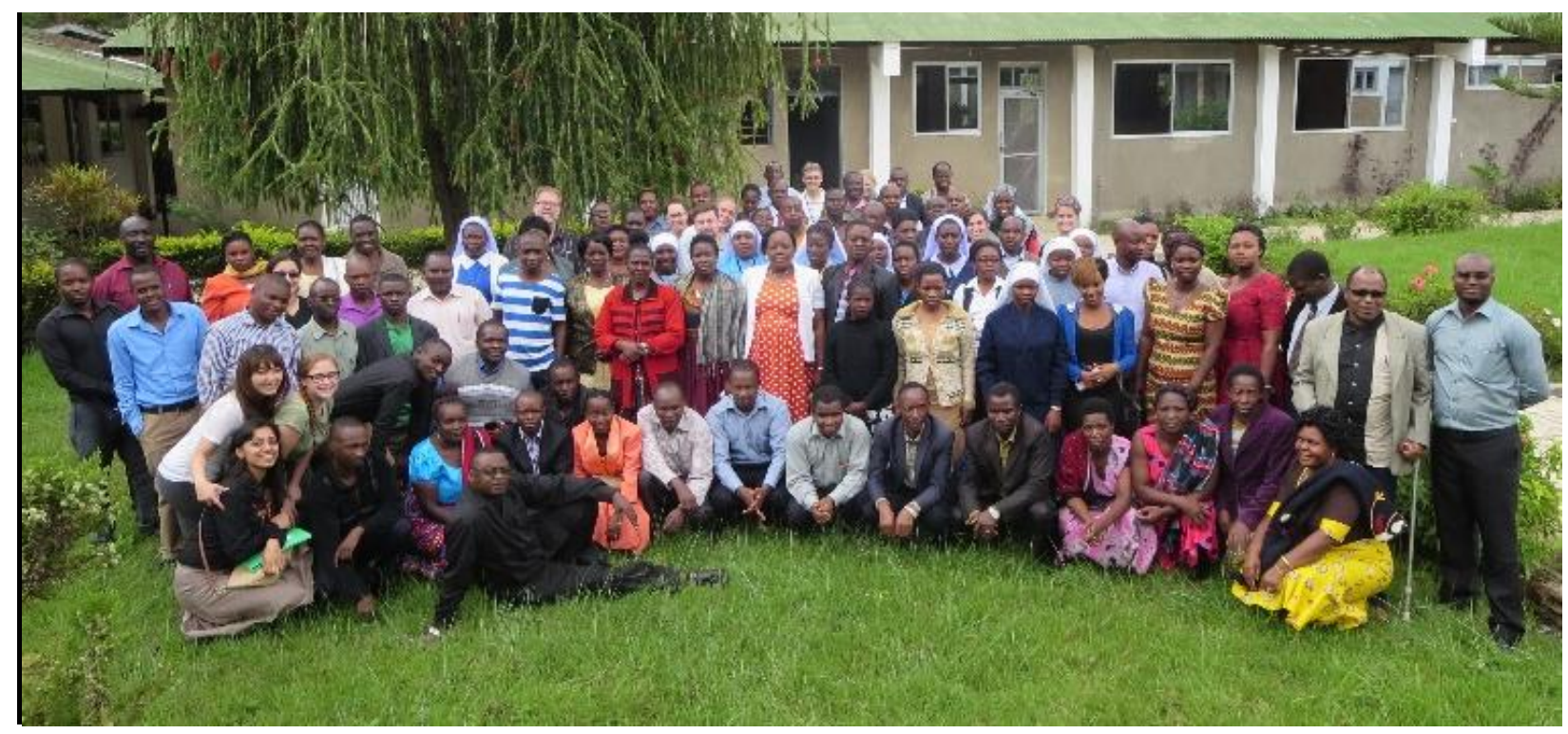

\section{References}

1. Kerry VB, Ndung'u T, Walensky RP, Lee PT, Kayanja VFIB, Bangsberg DR. Managing the demand for global health education. PLoS Med PLoS Medicine. 2011 Aug;8(11).

http://dx.doi.org/10.1371/journal.pmed.1001118

2. Kotzee TJ, Couper ID. What interventions do South African qualified doctors think will retain them in rural hospitals of the Limpopo province of South Africa? Rural Remote Health. 2006;Jul-Sep;6(3):581. Epub 2006 Sep 6.

http://www.rrh.org.au/articles/subviewnew.asp?Articl eID $=581$

3. Frenk J, Chen L, Bhutta ZA, Cohen J, Crisp N, Evans $\mathrm{T}$, et al. Health professionals for a new century: transforming education to strengthen health systems in an interdependent world. The Lancet.

2010;376(9756):1923-58. http://dx.doi.org/10.1016/S0140-6736(10)61854-5

4. Maki J, Qualls M, White B, Kleefield S, Crone R. Health impact assessment and short-term medical missions: a methods study to evaluate quality of care. BMC Health Serv Res. 2008 Feb;8(1). http://dx.doi.org/10.1186/1472-6963-8-121

5. Crump JA, Sugarman J. Ethics and best practice guidelines for training experiences in global health.
Am J Trop Med Hyg. 2010;83(6):1178-82.

http://dx.doi.org/10.4269/ajtmh.2010.10-0527

6. Bajkiewicz C. Evaluating short-term missions. J Christ Nurs. 2009;26(2):110-4.

http://dx.doi.org/10.1097/01.CNJ.0000348272.27924. 24

7. Coors ME, Matthew TL, Matthew DB. Ethical precepts for medical volunteerism: including local voices and values to guide RHD surgery in Rwanda: Table 1. J Med Ethics. 2015Nov;41(10):814-9. http://dx.doi.org/10.1136/medethics-2013-101694

8. Karle H. Global standards and accreditation in medical education: a view from the WFME. Acad Med. 2006;81(Supplement).

http://dx.doi.org/10.1097/01.acm.0000243383.71047. $\underline{\mathrm{c} 4}$

9. Habbick BF, Leeder SR. Orienting medical education to community need: a review. Med Educ. 1996;30(3):163-71. http://dx.doi.org/10.1111/j.13652923.1996.tb00738.x

10. Walker GJA. Medical care in developing countries: assessment and assurance of quality. evaluation $\&$ the health professions. 1983 Jan;6(4):439-52. http://dx.doi.org/10.1177/016327878300600405

11. Nicholas DD, Heiby JR, Hatzell TA. The quality assurance project: introducing quality improvement to primary health care In less developed countries. Int J 
Qual Health Care. 1991Jan;3(3):147-65. http://dx.doi.org/10.1093/intqhe/3.3.147

12. Gukas ID. 2009. Global paradigm shift in medical education: issues of concern for Africa. Med Teacher 9:887-92. http://dx.doi.org/10.1080/01421590701814286

13. The ACCME and the globalization of continuing medical education [Internet]. Accreditation Council for Continuing Medical Education. [cited 2016 Aug 20]. Available from: http://www.accme.org/newspublications/news/accme-and-globalizationcontinuing-medical-education

14. Campbell A, Sullivan M, Sherman R, Magee WP. The medical mission and modern cultural competency training. J Amer Coll Surg. 2011;212(1):124-9. http://dx.doi.org/10.1016/j.jamcollsurg.2010.08.019

15. Panosian C, Coates TJ. The new medical "missionaries" - grooming the next generation of global health workers. N Eng J Med. 2006;354(17):1771-3. http://dx.doi.org/10.1056/NEJMp068035

16. Framework for action on interprofessional education and collaborative practice. Geneva: World Health Organization; 2010. http://scholar.harvard.edu/hoffman/files/18_-_jah__overview_of_who_framework_for_action_on_ipe_a nd cp 2010 gilbert-yan-hoffman.pdf

17. O'Neil E. Who we are and might be. In: global health, excellence demands equity. Am J Kidney Diseases. 2008;51(1):145-54. http://dx.doi.org/10.1053/j.ajkd.2007.11.005

18. Capacity building in medical education and health outcomes. [Internet]. [cited 2016 Aug 20]. Available from:

http://www.educationforhealth.net/text.asp?2007/20/3 /65/101606

19. Langowski MK, Iltis AS. Global health needs and the short-term medical volunteer: ethical considerations. HEC Forum. 2011;23(2):71-8. http://dx.doi.org/10.1007/s10730-011-9158-5

20. Martiniuk AL, Manouchehrian M, Negin JA, Zwi AB. Brain gains: a literature review of medical missions to low and middle-income countries. BMC Health Serv Res. 2012;12(1). https://dx.doi.org/10.1186/14726963-12-134

21. Gordon PR, Carlson L, Chessman A, Kundrat ML, Morahan PS, Headrick LA. A multisite collaborative for the development of interdisciplinary education in continuous improvement for health professions students. Academ Med. 1996;71(9):973-8. http://dx.doi.org/10.1097/00001888-199609000$\underline{00012}$

22. Reerink E. Quality assurance in health care of developing countries. Int J Qual Health Care. 1989 Jan;1(4):197. http://dx.doi.org/10.1093/intqhe/1.4.197-a

23. Sykes KJ. Short-term medical service trips: a systematic review of the evidence. Am J Pub Heal. 2014;104(7). http://dx.doi.org/10.2105/AJPH.2014.301983

24. Berry NS. Did we do good? NGOs, conflicts of interest and the evaluation of short-term medical missions in Sololá, Guatemala. Social Science \& Medicine. 2014;120:344-51. http://dx.doi.org/10.1016/j.socscimed.2014.05.006

25. Barry MM, Allegrante JP, Lamarre M-C, Auld ME, Taub A. The Galway Consensus Conference: international collaboration on the development of core competencies for health promotion and health education. Glob Heal Promo. 2009;16(2):05-11. http://dx.doi.org/10.1177/1757975909104097

26. Houpt ER, Pearson RD, Hall TL. Three domains of competency in global health education: recommendations for all medical students. Acad Med. 2007;82(3):222-5. http://dx.doi.org/10.1097/ACM.0b013e3180305c10

27. Drain PK, Primack A, Hunt DD, Fawzi WW, Holmes KK, Gardner P. Global health in medical education: a call for more training and opportunities. Acad Med. 2007;82(3):226-30. http://dx.doi.org/10.1097/ACM.0b013e3180305cf9

28. Bills CB, Ahn J. Global health education as a translational science in graduate medical education. $\mathrm{J}$ Grad Med Educ. 2015;7(2):166-8. http://dx.doi.org/10.4300/JGME-D-14-00319.1

29. Strand MA, Chen AI, Pinkston LM. Developing cross-cultural healthcare workers: content, process and mentoring. Christ J Glob Heal. 2016;3(1):57. http://dx.doi.org/10.15566/cjgh.v3i1.102

30. Iserson KV, Biros MH, Holliman CJ. Challenges in international medicine: ethical dilemmas, unanticipated consequences, and accepting limitations. Acad Emer Med. 2012;19(6):683-92. http://dx.doi.org/10.1111/j.1553-2712.2012.01376.x

31. Abram FY. Reverse mission: a model for international social work education and transformative intra- 
national practice. Int Social Work. 2005

Jan;48(2):161-76. http://dx.doi.org/10.1177/0020872805050490

32. Montgomery LM. Short-term medical missions: enhancing or eroding health? Missiology: an Int Rev. 1993;21(3):333-41. http://dx.doi.org/10.1177/009182969302100305

33. Isaacson G, Drum ET, Cohen MS. Surgical missions to developing countries: ethical conflicts. Otolaryn Head Neck Surg. 2010;143(4):476-9. http://dx.doi.org/10.1016/j.otohns.2010.05.011
34. Willis-Shattuck M, Bidwell P, Thomas S, Wyness L, Blaauw D, Ditlopo P. Motivation and retention of health workers in developing countries: a systematic review. BMC Health Serv Res. 2008;8(1). http://dx.doi.org/10.1186/1472-6963-8-247

35. Ott BB, Olson RM. Ethical issues of medical missions: the clinicians' view. HEC Forum. 2011;23(2):105-13. http://dx.doi.org/10.1007/s10730$\underline{011-9154-9}$

Peer Reviewed

Competing Interests: None declared.

Acknowledgments: The authors would like to thank our parent organization, Shoulder to Shoulder, for support, organization and inspiration. We would like to thank our generous donors: Global Health Ministries, Peter J King Family Foundation, Dale and Patty Andersen, Arlene and Dave Tourville, and several anonymous donors. We would like to recognize Mr. Sylvester Udope, Christian Social Services Commission Southern Zone Manager, for his tremendous help in planning for the conference and assisting with conduct and presenting at the conference. We would also like to thank Yunfa Sovelo MD, Mr. Alamu Kikoti, Mr. Nayman Chavalla, Ritha Tesha RN, and Tuliwumi Hingi RN for ongoing support and hospitality. We would like to thank our volunteer faculty for donating their time and resources to participate in our conference. Finally, we would like to thank the entire staff and community at ILH for welcoming us to partner in improving the health of Southern Tanzania.

Correspondence: John Kvasnicka, MD, MBA jkvasnicka@healtheast.org

Cite this article as: Kvasnicka J, Olson K, Saga M, Danda I, Hurley R, Moody G, Wilke C. Teaching quality improvement in Tanzania: a model of inter-professional partnership for global health development. Christian Journal for Global Health. Mar 2017; 4(1):34-45.

(C) Kvasnicka J, Olson K, Saga M, Danda I, Hurley R, Moody G, Wilke C This is an open-access article distributed under the terms of the Creative Commons Attribution License, which permits unrestricted use, distribution, and reproduction in any medium, provided the original author and source are properly cited. To view a copy of the license, visit https://creativecommons.org/licenses/by/4.0/

$$
\text { www.cjgh.org }
$$

Mar 2017. Christian Journal for Global Health, 4(1): 34-45. 


\section{Appendix}

\begin{tabular}{|c|c|c|c|c|c|c|}
\hline \multirow{2}{*}{\begin{tabular}{|l} 
Evaluation Form \\
PLEASE RATE THE OVERALL VALUE OF THE CONFERENCE
\end{tabular}} & \multicolumn{6}{|c|}{$\begin{array}{l}\text { RATING (Rate } 1-5) 1=\text { not valuab } \\
5=\text { very valuable }\end{array}$} \\
\hline & 1 & 2 & 3 & 4 & 5 & \\
\hline \multicolumn{7}{|l|}{ PLEASE RATE THE VALUE OF EACH TOPIC } \\
\hline Quality Improvement: Pfeiffer/Jensen & 1 & & 2 & 3 & 4 & 5 \\
\hline Keynote Address: Sterile Technique: Kitundu & 1 & & 2 & 3 & 4 & 5 \\
\hline Co-Leadership: Plooster & 1 & & 2 & 3 & 4 & 5 \\
\hline Wound Care: Hussein & 1 & & 2 & 3 & 4 & 5 \\
\hline Cleaning, Disinfection, and Sterilization: Holmuth & 1 & & 2 & 3 & 4 & 5 \\
\hline Peripheral IV line insertion and maintainance: Jennerjohn/Gornall & 1 & & 2 & 3 & 4 & 5 \\
\hline Insulin and Goals of Diabetes Therapy: Kayworth & 1 & & 2 & 3 & 4 & 5 \\
\hline Cancer Care: Hurley & 1 & & 2 & 3 & 4 & 5 \\
\hline Rheumatologic Diseases: Ramdass & 1 & & 2 & 3 & 4 & 5 \\
\hline HIV Associated Malignancies: Rangaraju & 1 & & 2 & 3 & 4 & 5 \\
\hline BPH: Olson & 1 & & 2 & 3 & 4 & 5 \\
\hline Public Health and Nutrition: Saga & 1 & & 2 & 3 & 4 & 5 \\
\hline Hand Hygiene: Holmuth & 1 & & 2 & 3 & 4 & 5 \\
\hline Chikungunya: Creech & 1 & & 2 & 3 & 4 & 5 \\
\hline Pharmacy Stock Outs: Hwang & 1 & & 2 & 3 & 4 & 5 \\
\hline HIV Update: Mziray & 1 & & 2 & 3 & 4 & 5 \\
\hline Contraception: Anderson & 1 & & 2 & 3 & 4 & 5 \\
\hline Develop Quality Improvement Plans & 1 & & 2 & 3 & 4 & 5 \\
\hline Breakout: Community Based Primary Health Care: Jensen & 1 & & 2 & 3 & 4 & 5 \\
\hline Breakout: Administrative Keynote: Kikoti & 1 & & 2 & 3 & 4 & 5 \\
\hline Breakout: CBPHC Workshop/Learning Circles & 1 & & 2 & 3 & 4 & 5 \\
\hline
\end{tabular}

Are you a... Physician Nurse Pharmacist Administrator Other

Has your competence increased in Objective 1, understanding concepts and techniques in medical care in the acute hospital setting? Yes No Je uwezo wako umeongezeka katika lengo la Kwanza

Has your competence increased in Objective 2, understanding practices in US and Tanzania hospitals? Yes No

Je uwezo wako umeongezeka katika lengo la Pili

Has your competence increased in Objective 3, developing quality improvement action plans? Yes No

Je uwezo wako umeongezeka katika lengo la Tatu

This activity has impacted my clinical practice, competence or patient care outcomes. Shughuli hii imeathiri mazoezi kliniki, uwezo au kutawanya matokeo yangu.

$$
\text { Strongly Agree Agree Neutral Disagree Strongly Disagree }
$$

Was the presentation fair and free from bias? llikuwa onyesho haki na huru bila upendeleo Yes No

Was the presenter fair and free from bias? Alikuwa mtangazaji wa haki na huru bila upendeleo Yes No

Please tell us the most important things you learned Tafadhali Tuambie mambo muhimu uliojifunza

Please tell us of any bias (upendeleo) you found Tafadhali Tuambie mapendeleo wowote ulio kutana

What else would you like us to know? Ungependa nini kingine sisi kujua?

What would you like to have us teach about next year? Je utapenda tufundishe mambo gani kuhusu mwaka ujao?

Mar 2017. Christian Journal for Global Health, 4(1): 34-45. 